\begin{tabular}{|c|c|}
\hline \multirow{3}{*}{ 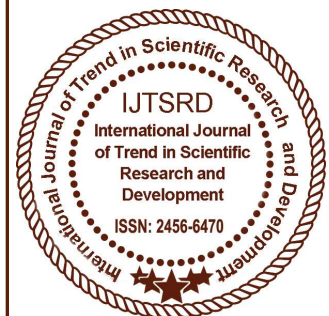 } & $\begin{array}{l}\text { International Journal of Trend in Scientific } \\
\text { Research and Development (IJTSRD) }\end{array}$ \\
\hline & International Open Access Journal \\
\hline & ISSN No: 2456 - 6470 | www.ijtsrd.com | Volume - 2 | Issue - 1 \\
\hline
\end{tabular}

\title{
A Descriptive Study on Assessment of Knowledge regarding Menstrual Hygiene among the Adolescent Girls in PUC, Dayananda Sagar Institution, Bengaluru.
}

\author{
Jyoti Laxmi Chetty \\ Assistant Professor, Dayananda Sagar University, \\ Bengaluru, Karnataka, India
}

\section{ABSTRACT}

A descriptive study on assessment of knowledge regarding menstrual hygiene among the adolescent girls in PUC, Dayananda Sagar Institution, Bangalore carried out by Ms.Susanti Kath, Ms. Tara Ghale, Ms. Pooja Rai, Ms. Mamta Sharma, Mr. Roshin George, Mr. Gotau Bitrus Yusuf and Ms. Asha in partial fulfillment of the requirement of IV year BSc. Nursing, Dayananda Sagar College Of Nursing, Kumaraswamy Layout, Bangalore.The objectives of the study are to assess the knowledge of adolescent girls regarding menstruation and menstrual hygiene among PUC students of Dayananda Sagar Institution, Kumaraswamy layout.A group of 100 adolescent girls were selected for the study in Kumaraswamy layout, Bangalore; a descriptive study approach was used to assess the knowledge of adolescent girls. Review of Literature was done by the investigator which helped in preparation of the data tool collection. A structured interview schedule was developed to assess the knowledge of adolescent girls regarding menstrual hygiene.Knowledge of the adolescent girls regarding menstrual hygiene were assured of the confidentially of their responses, validity of the tools was done by the experts in the field of nursing/the data obtained using these tools were analyzed in forms of descriptive statistics. Significant findings of the study are; $-72 \%$ has adequate knowledge $-28 \%$ has moderate knowledge And interestingly to note that none of the adolescent girls had inadequate knowledge regarding menstrual hygiene.

Keywords: Knowledge; Menstruation; RTI

\section{INTRODUCTION}

Strive not to be a success but rather to be of value Albert Einstein.

Menstrual hygiene is an issue that is insufficiently acknowledged and has not received adequate attention in the reproductive health and Water, Sanitation and Hygiene (WASH) sectors in developing countries including India and its relationship with and impact on achieving many Millennium Development Goals (MDGs) is rarely acknowledged.

Studies that make the issue visible to the concerned policymakers and inform practical actions are very much warranted.

Menstruation is a phenomenon unique to the females. The first menstruation (menarche) occurs between 11 and 15 years with a mean of 13 years. Menstruation is still regarded as something unclean or dirty in Indian society.

The interplay of socio-economic status, menstrual hygiene practices and RTI are noticeable. Women having better knowledge regarding menstrual hygiene and safe practices are less vulnerable to RTI and its consequences. Therefore, increased knowledge about menstruation right from childhood may escalate safe practices and may help in mitigating the suffering of millions of women. With this background the present study was undertaken to assess the knowledge, beliefs, and source of information regarding menstruation among the adolescent school girls of the 
secondary school and also to identify the status of menstrual hygiene among them.

\section{BACKGROUND OF STUDY:}

According to WHO (2002):

The menstrual hygiene practices of woman during menstruation are of considerable importance as it has a health impact in terms of increased vulnerability of infection which in turn causes increased reproductive morbidity.

Few studies done in the past have acknowledge the association between menstrual hygiene and reproductive tract infections. They decided the need to improve the housing conditions with respect to basic facilities. There is a need to make available sanitary napkins at affordable prices.

Dr.Shamima Yasmin, Dr.Nirmalya Manna, Dr.SarmilaMallik ,Dr.Ashfaque Ahmed , Dr.BaisakhiParia(2010), in their study of review on menstrual hygiene among adolescents showed lack of appropriate and sufficient information about menstrual hygiene can be attributed to cultural and religious beliefs and taboos. Their findings reinforce the need to encourage safe and hygienic practices among the adolescent girls and bring them out of traditional beliefs, misconceptions and restrictions regarding menstruation. General awareness about cause, organs involved in menstruation was to be improved. Use of sanitary napkins was to be enhanced by social marketing.For using old washed cloth, proper hygiene was to be maintained. Incorrect restrictions, myths and beliefs associated with menstruation can be removed by the help of teachers and parents.

\section{OBJECTIVES OF STUDY:}

1. To determine the knowledge of adolescent girls regarding menstruation.

2. To determine the knowledge level of adolescent girls regarding menstrual hygiene.

\section{OPERATIONAL DEFINITION:}

KNOWLEDGE: Refers to the ability and understanding of adolescent girls as elicited by the structured interview schedule.
MENSTRUAL HYGEINE: It means the practices of women during menstruation to decrease the vulnerability of infection and to decrease reproductive morbidity.

ADOLESCENT GIRLS: Adolescent girls are those age groups who belong to the period between and maturity. i.e. 12-21 years.

\section{ASSUMPTIONS:}

1. Adolescent girls will have some knowledge regarding menstrual hygiene and practices during menstrual hygiene.

2. Adolescent girls may have either positive or negative attitude towards menstrual hygiene.

3. An adequate knowledge on menstrual hygiene will prevent reproductive morbidity.

\section{HYPOTHESIS:}

H1. Adolescent girls do not have adequate knowledge regarding menstrual hygiene.

H2. Adolescent girls have negative attitude towards menstrual hygiene.

\section{DELIMITATIONS:}

1. The study is delimited to adolescent girls studying in I PUC school of DSI.

2. The study is delimited to people who can understand Kannada and English.

\section{RESEARCH METHODOLOGY}

This chapter describes the methodology to assess the knowledge on menstrual hygiene among adolescent girls of PUC studying in Dayananda Sagar Institute.

Methodology includes the description of research design, variable, setting of study, population, sample, criteria for selection of sample, sampling technique, development and description of tool, content validity, reliability, pilot study, data collection and plan for data analysis.

\section{RESEARCH DESIGN:}

The design chosen to assess the knowledge on menstrual hygiene was a non-experimental survey 
design that helps to provide factual information about existing phenomenon.

\section{VARIABLES:}

The study variables are knowledge and menstrual hygiene .The demographic variables are:

-Age
-Religion
-Educational status of Mother
-Family Type
-Birth Order
-Use of Technology

\section{SETTING OF STUDY:}

The setting of study was at PUC of Dayananda Sagar Institutions, Kumaraswamy Layout.

\section{POPULATION:}

The study population comprised of all the Adolescent Girls of PUC of Dayanada Sagar Institution, Kumaraswamy Layout.

\section{SAMPLE:}

The adolescent girls who fulfilled the inclusive criteria constituted the study sample.

\section{CRITERIA FOR SELECTION OF SAMPLE:}

Inclusive Criteria: The adolescent girls who are willing to take part in the programme.

Exclusive Criteria: Adolescent girls who cannot understand language except Kannada and English.

\section{SAMPLE SIZE:}

The sample size was 100 adolescent girls among PUC students.

\section{SAMPLING TECHNIQUE:}

The study subjects were chosen by Non-Random Convenient Technique.

\section{DEVELOPMENT AND DESCRIPTION OF TOOLS:}

With the extensive review of literature and discussion with the nursing experts, a structured interview schedule was developed to assess the knowledge of adolescent girls on menstrual hygiene. The tool was in English for the convenience of data collection procedure.

\section{DATA ANALYSIS}

This chapter deals with the analysis of data collected from a100 adolescent girls of Dayananda Sagar PU College $\left(11^{\text {th }}\right.$ standard/ +1$)$ to assess their knowledge on menstrual hygiene.

The data findings have been analyzed and tabulated according to the plan for data analysis and are interpreted.

\section{ORGANISATION OF DATA:}

This has 2 section, Section A and Section B:

Section A: Dealt with the demographic variables such as age, birth order, family type, educational status of the mother, religion, and use of technology.

Section B: Dealt with the knowledge on menstrual hygiene. It had 2 sub sections.

Part I- General Knowledge on Menstruation Part II- Knowledge on Menstrual Hygiene (Section B has 25 items)

Section A:

Description of the demographic variable of 100 adolescent girls of Dayananda Sagar PU College $\left(11^{\text {th }}\right.$ Standard $/+1$ 
Table 1: Frequency and percentage, distribution of adolescent girls by age, religion, family type, educational status of mother, birth order, and use of technology

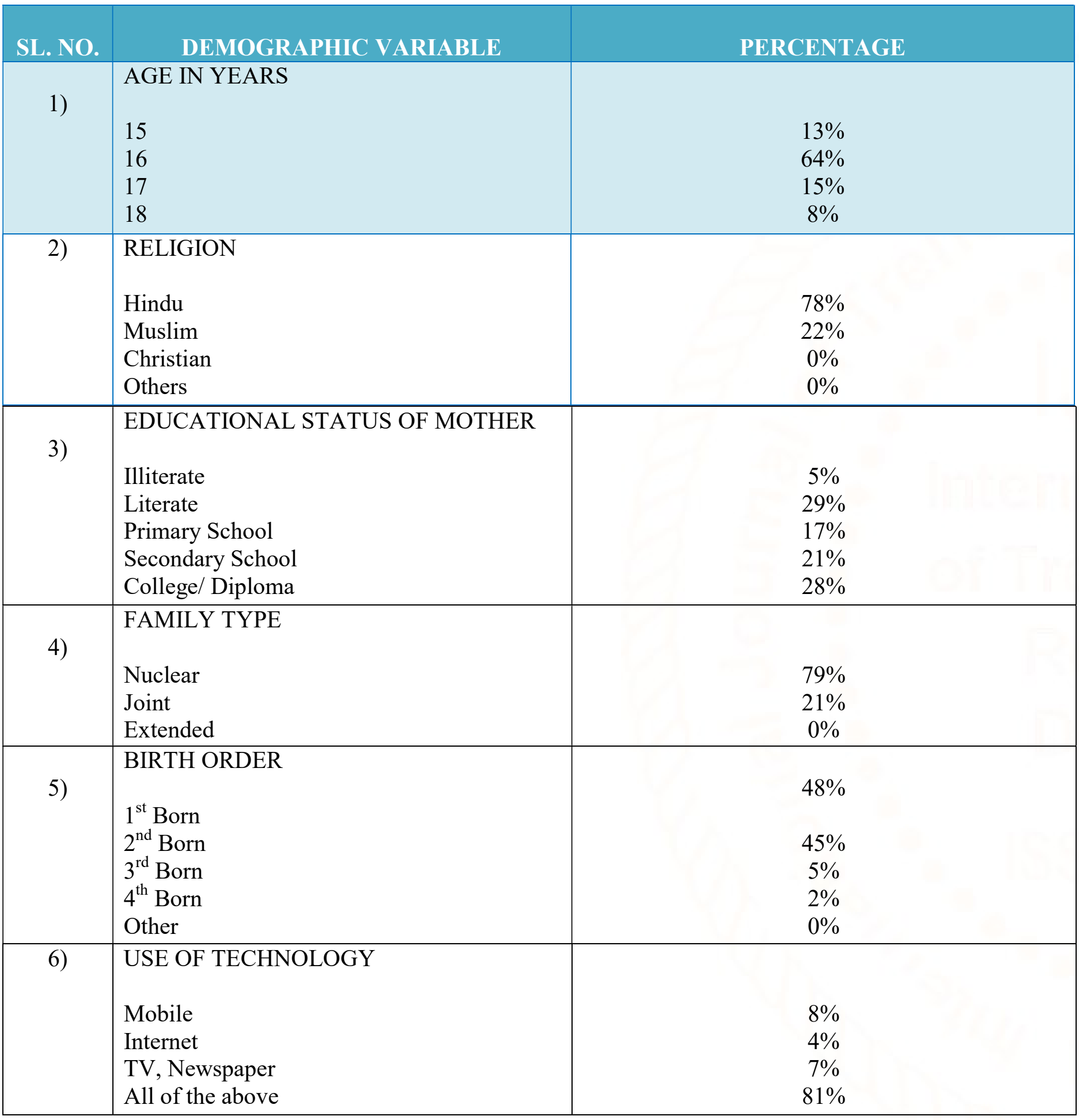

Table I depicts the frequency and percentage of adolescent girls by age in years, religion of each girl, family type, educational status of mother, birth order, and use of technology.

In regards to age, a majority of the adolescent girls were 16 years old $(64 \%)$. The girls that were 15 years old were $13 \%$. The girls who were 17 years old were $15 \%$. And the girls who were 18 years old were $8 \%$.
Considering the educational status of their mothers, there were $5 \%$ Illiterate mothers, $29 \%$ literate mothers, $17 \%$ of mothers attended Primary schools, $21 \%$ of mothers attended Secondary School, and 28\% of mothers have attended college/ diploma.

In regards to the Family Type, 79\% of girls live in a Nuclear Family. 21\% of girls live in a Joint Family. And 0\% lives in an Extended Family. Considering the 
International Journal of Trend in Scientific Research and Development (IJTSRD) ISSN: 2456-6470

Birth Order, $48 \%$ are $1^{\text {st }}$ Born. $45 \%$ are $2^{\text {nd }}$ Born, $5 \%$ are $3^{\text {rd }}$ Born, $2 \%$ are $4^{\text {th }}$ Born and $0 \%$ is Other Born. In regards to the Use of Technology, $8 \%$ Use the Mobile. 4\% use Internet. 7\% use TV/Newspaper. And $81 \%$ use All the above Technology.

\section{DEMOGRAPHIC VARIABLES}

1) AGE IN YEARS

\section{PERCENTAGE DISTRIBUTION ADOLESCENT GIRLS BY AGE}

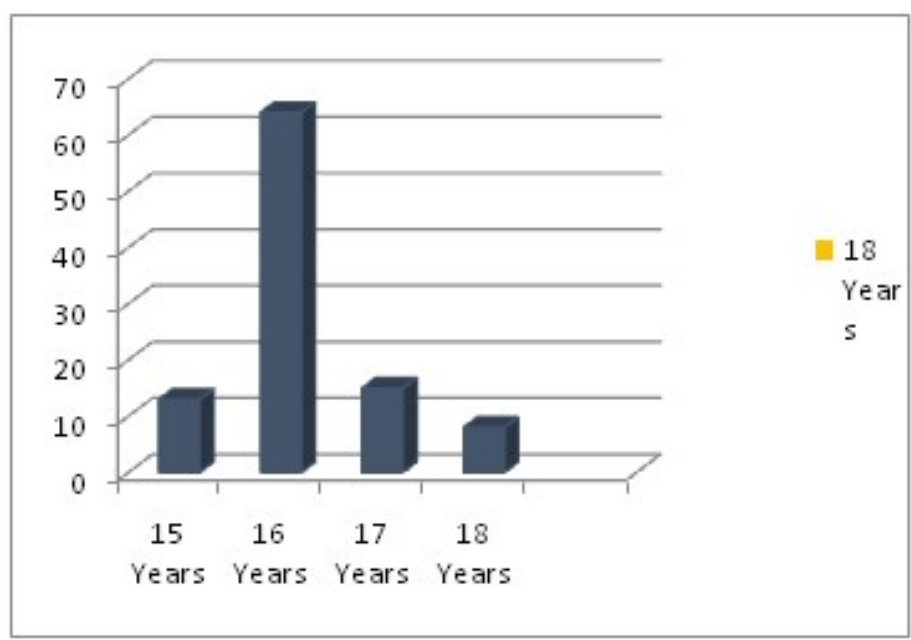

$\underline{\text { Age in years }}$

2) RELIGION OF THE ADOLESCENT GIRLS PERCENTAGE OF RELIGIONS OF THE ADOLESCENT GIRLS

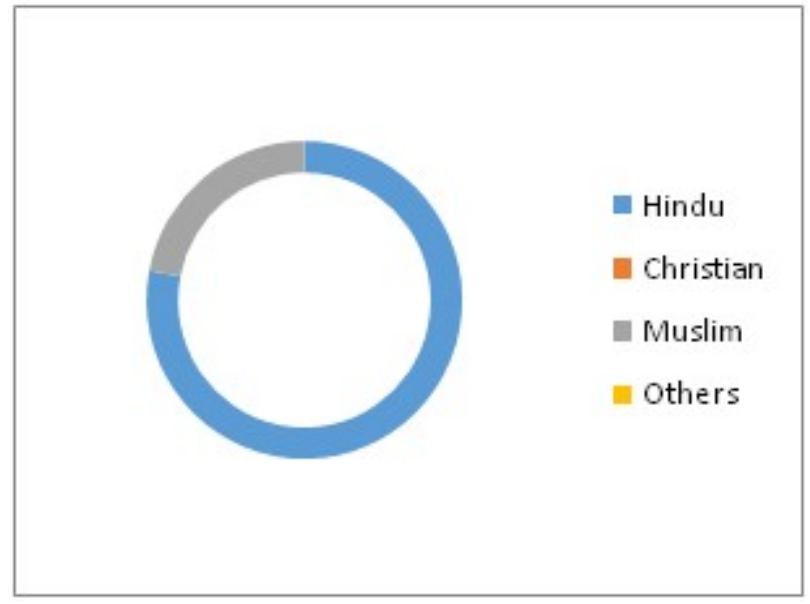

3) EDUCATIONAL STATUS OF THE MOTHER PERCENTAGE OF GIRLS ACCORDING TO THEIR MOTHER'S EDUCATIONAL STATUS

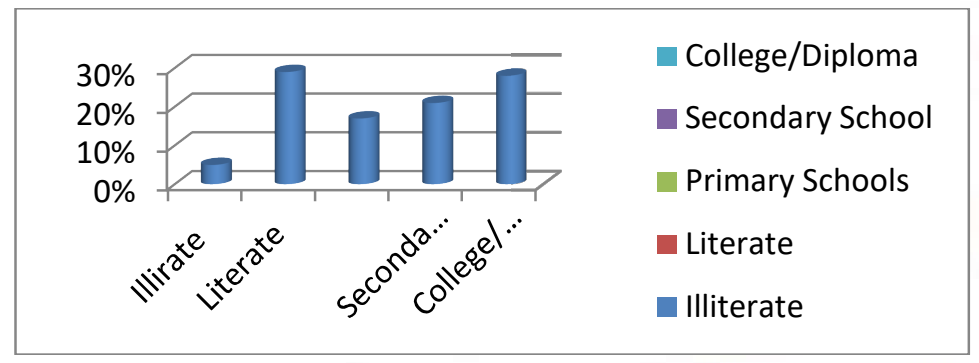

4) FAMILY TYPE

PERCENTAGE OF GIRLS ACCORDING TO THEIR FAMILY TYPE

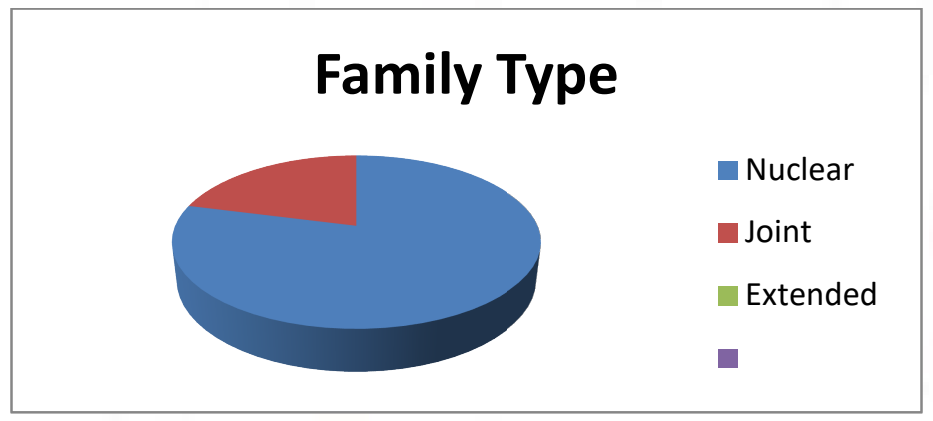

5) BIRTH ORDER

PERCENTAGE OF GIRLS ACCORDING TO THEIR BIRTH ORDER

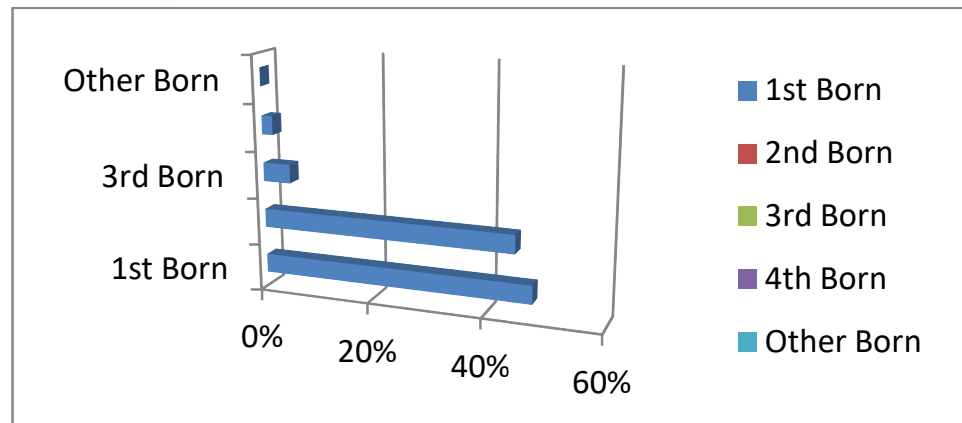




\section{6) USE OF TECHNOLOGY}

PERCENTAGES OF GIRLS ACCORDING TO

THEIR USE OF TECHNOLOGY

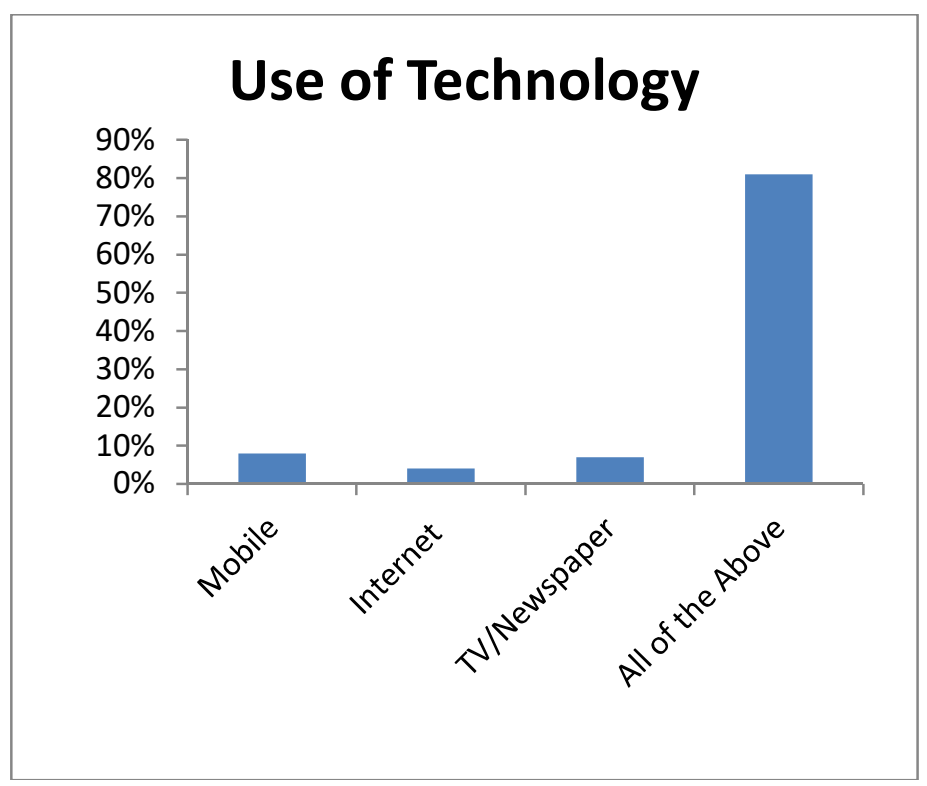

\section{SECTION B:}

Assessment of knowledge of adolescent girls on menstrual hygiene.

Table 2(a): Frequency and percentage distribution of level of knowledge among the adolescent girls.

\section{SECTION B:}

Assessment of knowledge of adolescent girls on menstrual hygiene.

Table 2(a): Frequency and percentage distribution of level of knowledge among the adolescent girls.

\begin{tabular}{|c|l|c|c|c|c|c|c|}
\hline \multicolumn{1}{|c|}{ Knowledge } & \multicolumn{2}{c|}{$<50 \%$} & \multicolumn{2}{c|}{$51-75 \%$} & \multicolumn{2}{c|}{$>75 \%$} \\
No. & \multicolumn{1}{|c|}{ No. } & \% & No. & No. & \% \\
\hline 1$)$ & $\begin{array}{l}\text { GENERAL KNOWLEDGE } \\
\text { ON MESTRAUTION }\end{array}$ & 1 & $1 \%$ & 29 & $29 \%$ & 70 & $70 \%$ \\
\hline 2$)$ & $\begin{array}{l}\text { KNOWLEDGE ON MENSTRUAL } \\
\text { HYGIENE }\end{array}$ & 1 & $1 \%$ & 44 & $44 \%$ & 55 & $50 \%$ \\
\hline 3$)$ & $\begin{array}{l}\text { OVERALL } \\
\text { KNOWLEDGE }\end{array}$ & 0 & $0 \%$ & 28 & $28 \%$ & 72 & $72 \%$ \\
\hline
\end{tabular}

Table 2(a): Depicts the Frequency and percentage distribution of the level of knowledge among adolescent girls.

In regards to general knowledge on menstrual hygiene it is evident that $29 \%$ of the adolescent girls had moderate knowledge, $70 \%$ had adequate knowledge, and $1 \%$ were inadequate knowledge.

Considering specific knowledge about menstrual hygiene, about $44 \%$ had moderate knowledge, 55\% had adequate knowledge, and $1 \%$ had inadequate knowledge.

In regards to overall knowledge status of adolescent girls regarding menstrual hygiene, it showed that a majority had adequate knowledge $72 \%$ and $28 \%$ had

moderate knowledge and it interesting to note that none of the adolescent girls had inadequate knowledge regarding menstrual hygiene.

\section{SECTION- B}

\section{1) GENERAL KNOWLEDGE ON MENSTRUATION}


International Journal of Trend in Scientific Research and Development (IJTSRD) ISSN: 2456-6470

Percentage Distribution of Adolescent Girls By General Knowledge On Menstruation

\section{Knowledge Level}

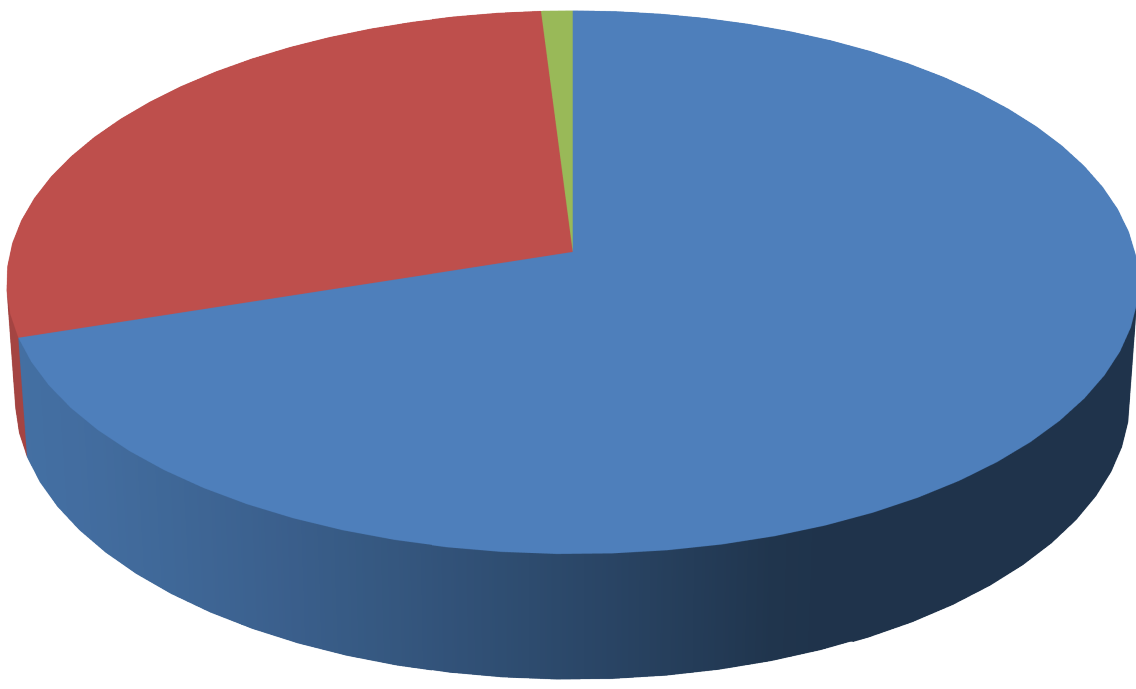

Adequete

Moderate

- Inadequate

2) GENERAL KNOWLEDGE ON MENSTRUAL HYGIENE

Percentage Of Adolescent Girls by Knowledge On Menstrual Hygiene

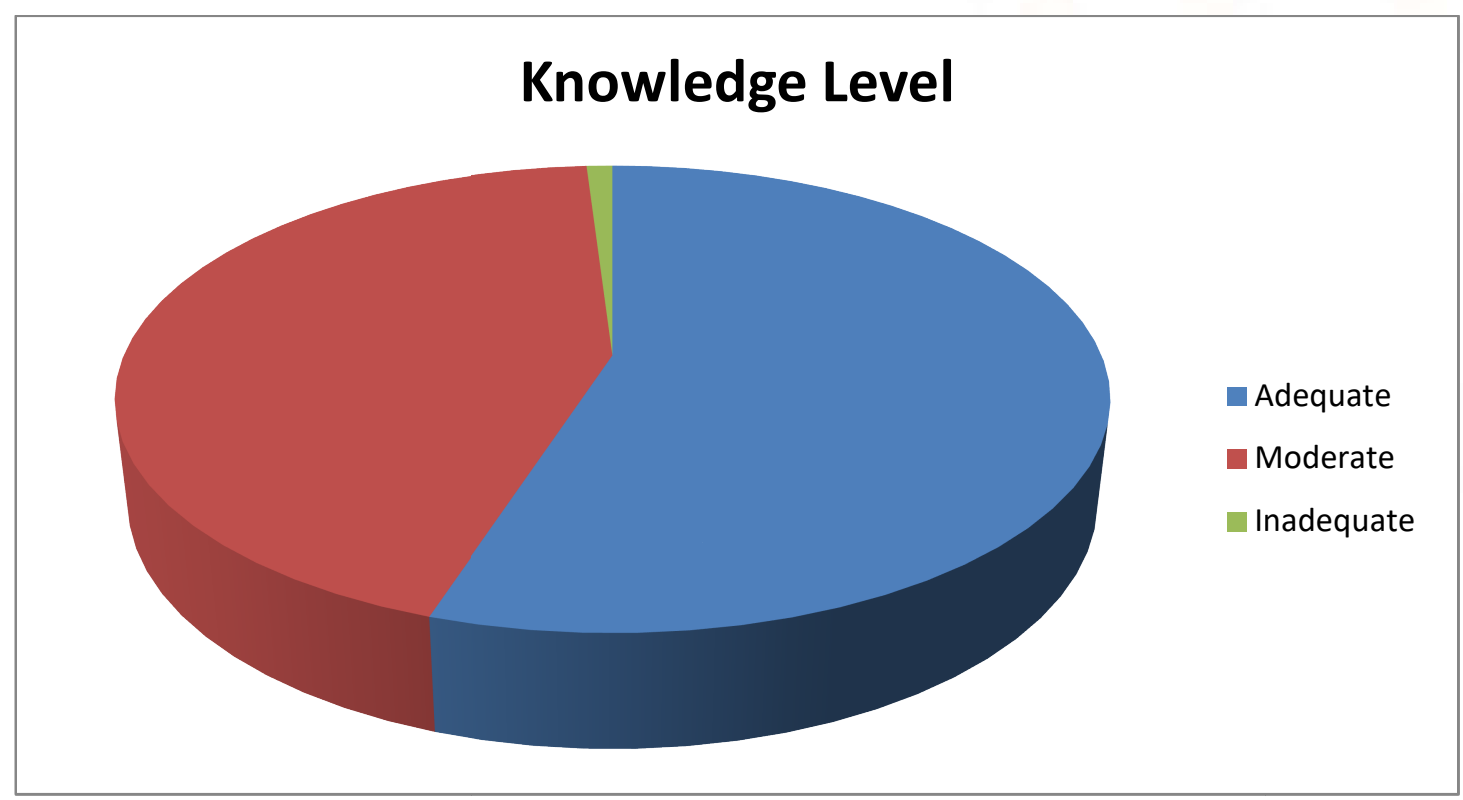




\section{3) OVERALL KNOWLEDGE}

Percentage Of Adolescent Girls By Overall Knowledge On Mentstrual Hygiene

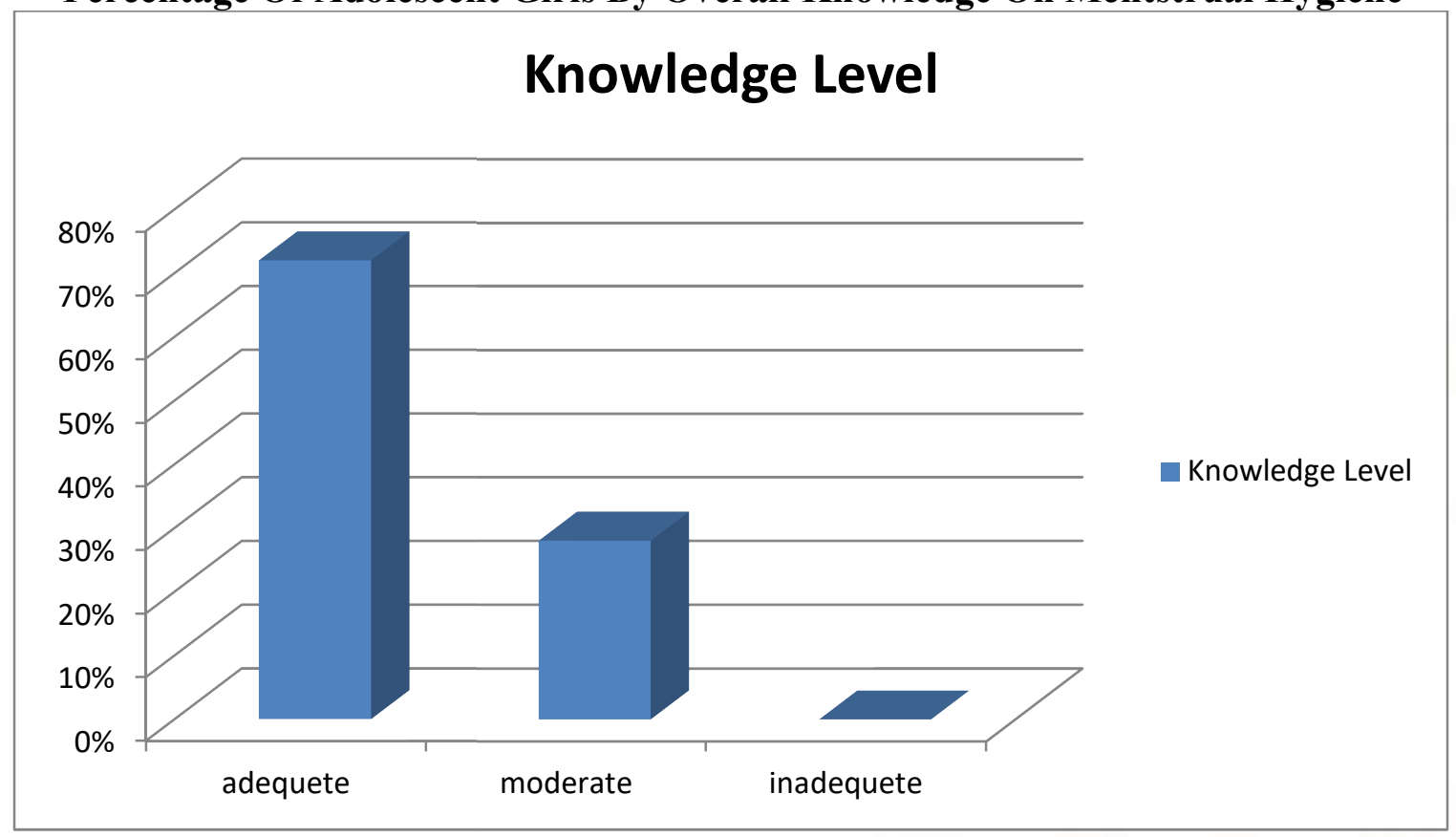

\section{RESULT ANALYSIS SUMMARY}

The objectives of the study is to determine the knowledge level of adolescent girls regarding menstrual hygiene with the demographic variables such as : -

Age, birth order, family type, educational status of mother, religion and use of technology .

The investigation assumes that the adolescent girls will have some knowledge regarding menstrual hygiene and prevent reproductive morbidity.

The need for studies is highlighted on the basis that adolescent girls will improve the knowledge regarding menstrual hygiene.

Review of literature reveals about the general knowledge of adolescent girls regarding menstrual hygiene.

It is a qualitative descriptive design study used in survey approach and the setting of study is at selected PUC college of Bangalore, Dayananda Sagar institution, Kumaraswamy layout.

The tool used to assess the knowledge is a structural interview schedule. It is obtained through review of literature and from the opinion of expert. The tool includes knowledge aspects of adolescent girls. The tools was tried on 100 adolescent girls to find out its clarity and feasibility to proceed with actual study.

\section{Major findings of the study}

1. Findings of the demographic variables, majority of the adolescent girls were 16 years old $(64 \%)$, the girls that were 15 years were $(13 \%)$, the girls who were 17 years old were $(15 \%)$ and the girls who were 18 years old were $(8 \%)$.

2. Finding of the level of general knowledge, $29 \%$ of the adolescent girls had moderate knowledge, $70 \%$ had adequate knowledge and $1 \%$ had inadequate knowledge.

3. Finding of the level of specific knowledge about $44 \%$ had moderate knowledge, 55\% had adequate knowledge, $1 \%$ had inadequate knowledge.

4. Finding of the level of overall knowledge status of adolescent girls regarding menstrual hygiene showed that $72 \%$ had adequate knowledge, $28 \%$ had moderate knowledge, and non of the adolescent girls had inadequate knowledge regarding menstrual hygiene .

\section{CONCLUSION}

The findings of the present study reveals that majority of adolescent girls had adequate knowledge that is $(72 \%)$ and $(28 \%)$ had moderate knowledge and interestingly non of the adolescent girls had inadequate knowledge regarding menstrual hygiene . This study findings highlights that there is adequate knowledge among the menstrual hygiene and most of 
the adolescent girls had positive attitude towards menstrual hygiene which contributes to prevent reproductive morbidity.

\section{REFERENCES}

1) DrShamima Yasmin , DrNirmalya Manna , DrSarmilaMallik, DrAshfaque Ahmed, DrBaisakhiParia, An indepth cross-sectional study in an urban community of WestBengal, India . IOSR Journal of Dental and Medical Sciences (IOSR-JDMS) e-ISSN: 2279-0853, p-ISSN: 22790861. Volume 5, Issue 6 (March- April. 2013), PP 22-26 www.iosrjournals.org.

2) Adolescent in India. profile.world health.organization.2003. Drakshayani Devi K, VenkataRamaiah P. A study on menstrual hygiene among rural adolescent girls.Indian J Med Sci. 1994 Jun 48 :139-43.

3) Dasgupta, Sarkar M. Menstrual Hygiene: How Hygienic is the Adolescent Girl ?Indian J Community Med. 2008 Apr;33 :77-80. Doi : 10.4103/0970-0218.40872.

4) Dongre Deshmukh PR, Garg BS. The effect of community-based health education intervention on management of menstrual hygiene among rural Indian adolescent girls. World Health Popul. 2007: 48-54.

5) Moawed SIndigenous practices of Saudi girls in Riyadh during their menstrual period.East Mediterr Health J. 2001 Jan-Mar:7 197-203.

6) Journal of pediatric \& Adolescent Gynaecology volume 19 , issue 4, August 2006, pg :271-275.

7) Verma , Pragya , Ahmed , S.Srivastava , Knowledge and practices about menstrual hygiene among Higher secondary school girls, Indian journal of community health, pg 265-217. Dec 2013. 